\title{
Naturally enhanced ion-acoustic lines at high altitudes
}

\author{
Y. Ogawa ${ }^{1,4}$, S. C. Buchert ${ }^{2}$, R. Fujii ${ }^{1}$, S. Nozawa ${ }^{1}$, and F. Forme ${ }^{3}$ \\ ${ }^{1}$ Solar Terrestrial Environment Laboratory, Nagoya University, Nagoya, Japan \\ ${ }^{2}$ Swedish Institute of Space Physics, Uppsala, Sweden \\ ${ }^{3}$ Centre d'Études des environnements Terrestre et Planétaires, Velizy, France \\ ${ }^{4}$ now at: National Institute of Polar Research, Tokyo, Japan
}

Received: 28 November 2005 - Revised: 6 November 2006 - Accepted: 27 November 2006 - Published: 21 December 2006

\begin{abstract}
Naturally enhanced ion-acoustic lines (NEIALs) between 1200 and $1900 \mathrm{~km}$ altitude are investigated. The NEIALs were found in the background gates of data from the European Incoherent Scatter (EISCAT) Svalbard radar (ESR) at $78^{\circ} \mathrm{N}$ looking field-aligned. Only strongly enhanced lines are detected at such high altitudes. The estimated enhancement above incoherent scattering integrated over the antenna beam and preintegration time of $10 \mathrm{~s}$ reaches about 10000 . Both lines are always enhanced above $1000 \mathrm{~km}$ altitude, and the downshifted line, corresponding to upward propagating ion-acoustic waves, is always stronger than the upshifted line, for downgoing waves. The ratio of the downshifted and upshifted peaks is often remarkably constant along a profile. Using the line positions as indicators of the ion-acoustic speeds and the bulk drift velocity, we find that the bulk drift does not exceed the ion-acoustic (sound) speed, but extrapolation of the profiles suggests that the sound barrier is reached around $2000 \mathrm{~km}$ in one event. The highest ion-acoustic speed is seen near $600 \mathrm{~km}$, above the density peak, indicating that electrons are heated not only by ionizing precipitation but significantly also by upgoing waves. Upflow continues to speed up above the estimated temperature maximum. A certain qualitative similarity to the solar corona seems to be the case.
\end{abstract}

Keywords: Ionosphere (Ionosphere-magnetosphere interactions; Plasma waves and instabilities; Wave-particle interactions)

\section{Introduction}

The so-called naturally enhanced ion-acoustic lines (NEIALs) discovered with incoherent scatter (IS) radar (Foster et al., 1988) have received considerable attention in

Correspondence to: Y. Ogawa

(yogawa@nipr.ac.jp) numerous studies. Great progress in observing their characteristics in space and time and in understanding the processes and waves causing the radar echo enhancements has been achieved. However, the causes are still not completely clear; and neither is the role of NEIALs in accelerating particles in the auroral plasma, or in creating small scale structures. These processes are believed to happen, perhaps mainly, in regions at several thousand kilometers altitude (the auroral acceleration region). NEIALs have been seen in the $F$ region and even $E$ region, in the height range accessible by normal IS measurements. Due to unexpectedly fortunate circumstances we have been able to investigate NEIALs at altitude up to about $1600 \mathrm{~km}$ and the results are presented here.

NEIALs are seen sporadically by ground-based IS radars located at high latitude. The scattered power is enhanced by typically a factor of up to 100 over integration times of a few seconds. The enhanced spectra are normally very asymmetric, one ion-acoustic shoulder being dominantly enhanced. This can be caused by very high electrical currents, by ion species drifting relative to each other, or by an electron beam creating Langmuir waves and their parametric decay (e.g. Rietveld et al., 1991; Collis et al., 1991; Wahlund et al., 1992; Forme, 1993). When the two antennas of the ESR are used as an interferometer, the spatial size of NEIALs perpendicular to the magnetic field is found to be sometimes less than $300 \mathrm{~m}$ (Grydeland et al., 2003, 2004). These measurements were done with high time resolution and it is suggested that NEIALs rise and decay over times of the order of only $200 \mathrm{~ms}$. Taking into account the spatial integration of normal IS measurements over the antenna beam and their time integration over at least several seconds, the true power enhancement over the incoherent scatter level must then be 4-5 orders of magnitude. NEIALs are often seen when looking along the magnetic field line and then they can emerge nearly simultaneously over several hundred kilometers along $B$. This geometry greatly favors detection by a radar looking

Published by Copernicus GmbH on behalf of the European Geosciences Union. 
field-aligned. However, the plasma wave vectors scattering the radar signal do not seem to be exclusively parallel to the magnetic field since NEIALs have been seen when the scattering vector was inclined to the magnetic field by many degrees. Electron temperature enhancement and upward ion flows are apparently associated with NEIALs.

Statistical studies of NEIALs detected with the EISCAT UHF radar indicate that the upshifted shoulder, corresponding to downward propagating waves, is more frequently enhanced than the downshifted shoulder (waves going upward) at altitudes below $300 \mathrm{~km}$. Conversely, the downshifted shoulder is enhanced more frequently at altitudes above $450 \mathrm{~km}$ (Rietveld et al., 1991, 1996). At altitudes between 300 and $450 \mathrm{~km}$, neither of the shoulders dominates statistically. Investigations using the UHF radar are limited to altitudes generally below $600 \mathrm{~km}$. NEIALs are more frequently observed with the EISCAT VHF radar $(224 \mathrm{MHz}$, $k_{\mathrm{VHF}} \approx 4 \mathrm{~m}^{-1}$, and $\left.\lambda_{\mathrm{VHF}}=1.34 \mathrm{~m}\right)$ than with the EISCAT UHF radar $\left(931 \mathrm{MHz}, k_{\mathrm{UHF}} \approx 9.1 \mathrm{~m}^{-1}\right.$, and $\left.\lambda_{\mathrm{UHF}}=0.32 \mathrm{~m}\right)$ (Cabrit et al., 1996). The difference may be due to the larger scattering volume of the VHF system, perhaps also because of the longer wave length. The distribution of the occurrence of the NEIALs as a function of universal time (UT) shows a general maximum occurrence in the time interval from 12:00 to 24:00 UT (approximately 14:00 to 02:00 magnetic local time) (Rietveld et al., 1996). The distribution probably reflects the times when the auroral oval is above Troms $\emptyset$ which is most likely in the evening.

In contrast, NEIALs observed with the EISCAT Svalbard radar $(\mathrm{ESR})\left(500 \mathrm{MHz}, k_{\mathrm{ESR}} \approx 21 \mathrm{~m}^{-1}\right.$, and $\left.\lambda_{\mathrm{ESR}}=0.60 \mathrm{~m}\right)$ near Longyearbyen are frequently seen around noon (e.g. Sedgemore-Schulthess et al., 1999; Ogawa et al., 2000a; Sedgemore-Schulthess and St.-Maurice, 2001). Due to its high latitude location the ESR is usually in or near the cusp in this time. A possible influence of the radar transmitter frequency on the enhanced power level of NEIALs has been investigated by analyzing separately the different channels of the ESR (Buchert et al., 1999; Ogawa et al., 2000b). In a few cases, plasma line enhancements in connection with NEIALs have been seen by Rietveld et al. (2002) and Strømme et al. (2005). The latter authors concluded that at least for these cases the parametric decay of Langmuir waves must cause the NEIALs.

Normally the IS signal obtained with the ESR allows a successful fit of plasma parameters at most up to about $800 \mathrm{~km}$ altitude. Therefore observational modes are not normally designed to obtain data from higher altitudes, and the characteristics of NEIALs have only been studied below about $800 \mathrm{~km}$ with the ESR. IS data from the EISCAT VHF radar in Troms $\varnothing$ can be fitted at altitudes up to $1800 \mathrm{~km}$. A disadvantage of the VHF is that the vertical antenna beam used makes an angle of about $13 \mathrm{deg}$ with the Earth's magnetic field line, and range profiles are therefore not profiles along the magnetic field line. Although NEIALs have certainly been seen above $1000 \mathrm{~km}$ with the VHF, to our knowl- edge no systematic study of them has been published yet.

Here we will show that the ESR can detect NEIALs above $1000 \mathrm{~km}$ altitude. Characteristics of such high-altitude NEIALs are investigated, and the question of their possible dependence on the radar frequency is also revisited.

\section{Measurement technique and data processing}

EISCAT Svalbard radar (ESR) observations are normally conducted using several channels with different transmitter frequencies. Before the year 2000 both so-called common Programmes run for the whole scientific community and several special Programmes run for individual users used a radar mode called "gup0". Long, uncoded pulses are transmitted on four different channels and subsequently received. The frequencies are separated by up to $2 \mathrm{MHz}$ in the version of gup0 that we had used in order to study NEIALs at different radar wave lengths (see Ogawa et al., 2000b). A detailed description of the gup0 mode has been given by Wannberg et al. (1997). By adapting the gup0 mode to use a wider frequency spacing, we had hoped to see a possible frequency dependence of the NEIALs corresponding to a different behavior at different wavelengths of the underlying waves or fluctuations. The frequencies of our version of gup0, called sp-ni-widefreq, are shown in Table 1. The maximum frequency difference, $3.8 \mathrm{MHz}$ is between channels 1 and 5. Data are averaged over $10 \mathrm{~s}$. Each channel is recorded separately.

Our sp-ni-widefreq uses the same pulse scheme as gup0. It is mainly intended for $F$ region and topside ionosphere observations, and covers the whole range between about $120 \mathrm{~km}$ and $900 \mathrm{~km}$. Figure 1 shows the timing diagram of the 8 channels used in gup0. In each of the two cycles, long pulses are transmitted on 4 different frequencies. Three of the pulses are transmitted for $360 \mu$ s, which corresponds to a range resolution of $54 \mathrm{~km}$. These pulses cover the range from 180 to $900 \mathrm{~km}$. The last pulse is shortened to $150 \mu$ s raising the height of the lower edge of the measurement to $122 \mathrm{~km}$ to reduce ground clutter effects (Wannberg et al., 1997). The range resolution of the last pulse is approximately $23 \mathrm{~km}$ and the pulse provides coverage from 123 to $750 \mathrm{~km}$. The receiver's sampling rate for gup0 is 20 us, corresponding to $3 \mathrm{~km}$ in range. The receiver of the ESR has 8 channels. 4 channels are normally used for sampling the signal. The rest of the channels are for sampling the background. When the transmitted pulse is between 1200 and $1900 \mathrm{~km}$, the signal is used for measuring the background noise data, since incoherently scattered echoes from such high altitudes are too weak to disturb the noise measurement. Unexpectedly we have found that strongly enhanced ion-acoustic lines (NEIALs) are seen in the background gates of gup0 and our sp-ni-widefreq. No reception of the radar echo occurs between about 900 and $1200 \mathrm{~km}$, the exact ranges vary between channels; consequently we have no information on 


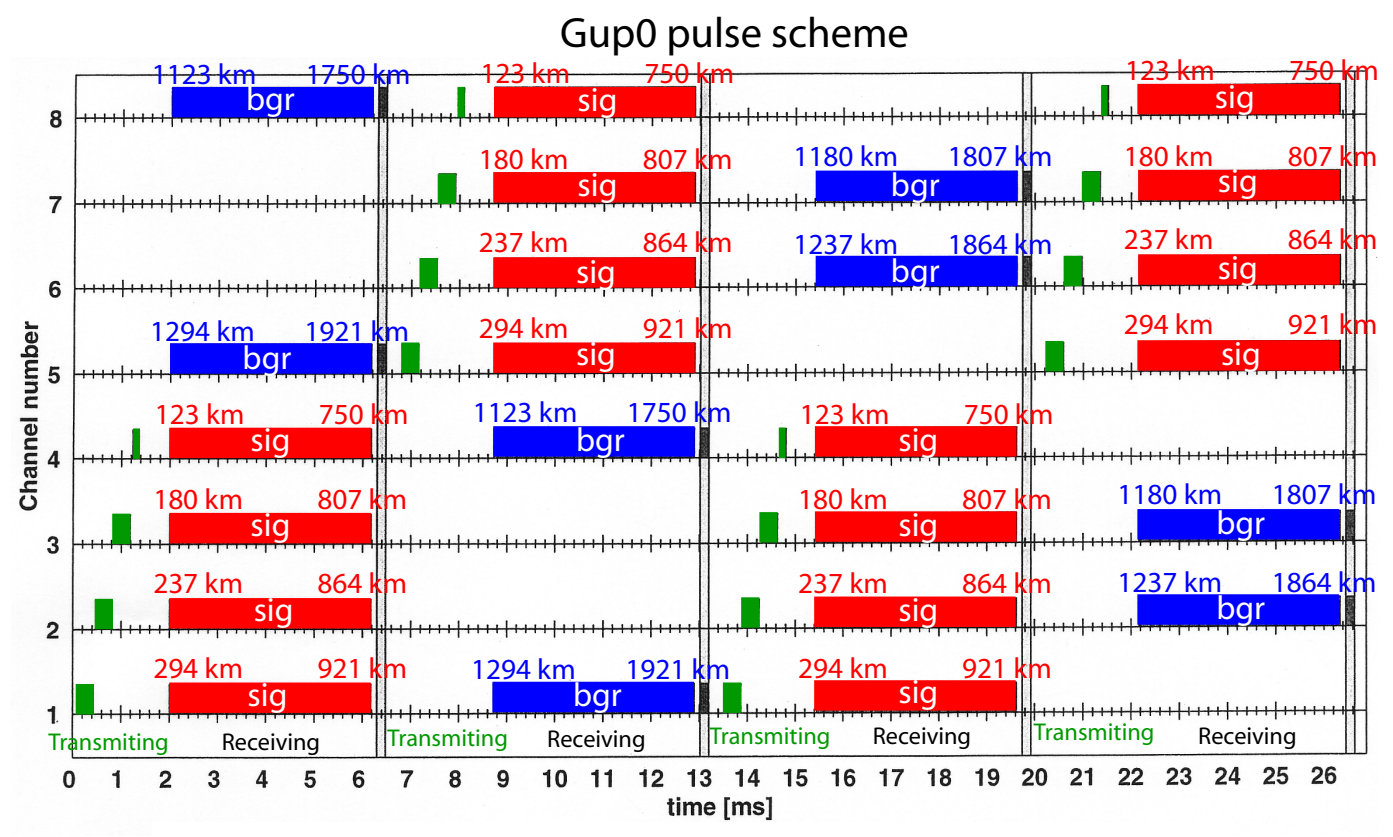

Fig. 1. Timing diagram for the 8 channels of the gup 0 program. Ranges are given for the first and last samples. The background noise is measured when the pulse is at a long range (between 1123 and $1921 \mathrm{~km}$, blue bars). Naturally enhanced ion-acoustic lines (NEIALs) in the background data therefore come from above $1000 \mathrm{~km}$ altitude when the ESR antenna is directed along the magnetic field.

Table 1. Channel parameters used in SP-NI-Widefreq at the ESR.

\begin{tabular}{cccccc}
\hline Channel Number & Transmitter Frequency & Pulse Length & Range & Altitude of signal gates & Altitude of background \\
\hline & $(\mathrm{MHz})$ & $(\mu \mathrm{s})$ & $(\mathrm{km})$ & $(\mathrm{km})$ & $(\mathrm{km})$ \\
2 & 498.100 & 360 & $294-865$ & $291-856$ & $1291-1856$ \\
3 & 498.900 & 360 & $237-808$ & $234-799$ & $1234-1799$ \\
4 & 500.125 & 360 & $180-751$ & $178-743$ & $1178-1743$ \\
5 & 500.375 & 150 & $123-694$ & $122-687$ & $1122-1687$ \\
6 & 501.900 & 360 & $294-865$ & $291-856$ & $1291-1856$ \\
7 & 501.100 & 360 & $237-808$ & $234-799$ & $1234-1799$ \\
8 & 499.875 & 360 & $180-751$ & $178-743$ & $1178-1743$ \\
\end{tabular}

NEIALs in that range interval. During the observation the ESR $32 \mathrm{~m}$ antenna was used, and it was directed along the magnetic field line, at azimuth $182.1^{\circ}$ and elevation $81.6^{\circ}$. We have searched semi-automatically through all preintegrated 10s data dumps on 28 July 2000 between 09:00 and 11:30 UT for NEIALs and other non-incoherent scatter spectra and obtained more than 200 spectra of NEIALs during the measurement. The preintegrated data dumps containing these NEIALs and other non-incoherent scatter spectra are removed before fitting the standard plasma parameters, electron density, ion and electron temperatures and ion velocity. For all preintegrated double-peaked spectra the highest power spectral density per unit frequency in each peak and its location in frequency have been determined. We have conducted observation of the dayside cusp region around 12 magnetic local time (MLT) over 4 days in July 2000. By far the largest number of NEIALs were detected on 28 July 2000 , when the geomagnetic activity level was disturbed. The Kp-index between 09:00 and 12:00 UT on 28 July 2000 was $4^{+}$.

\section{Results}

Figure 2 and 3 show typical spectra of NEIALs observed by the ESR on 28 July 2000. We plot spectra from all channels 1 to 8 between 150 and $920 \mathrm{~km}$ altitude, and also spectra of the background data between 1150 and $1650 \mathrm{~km}$ in 

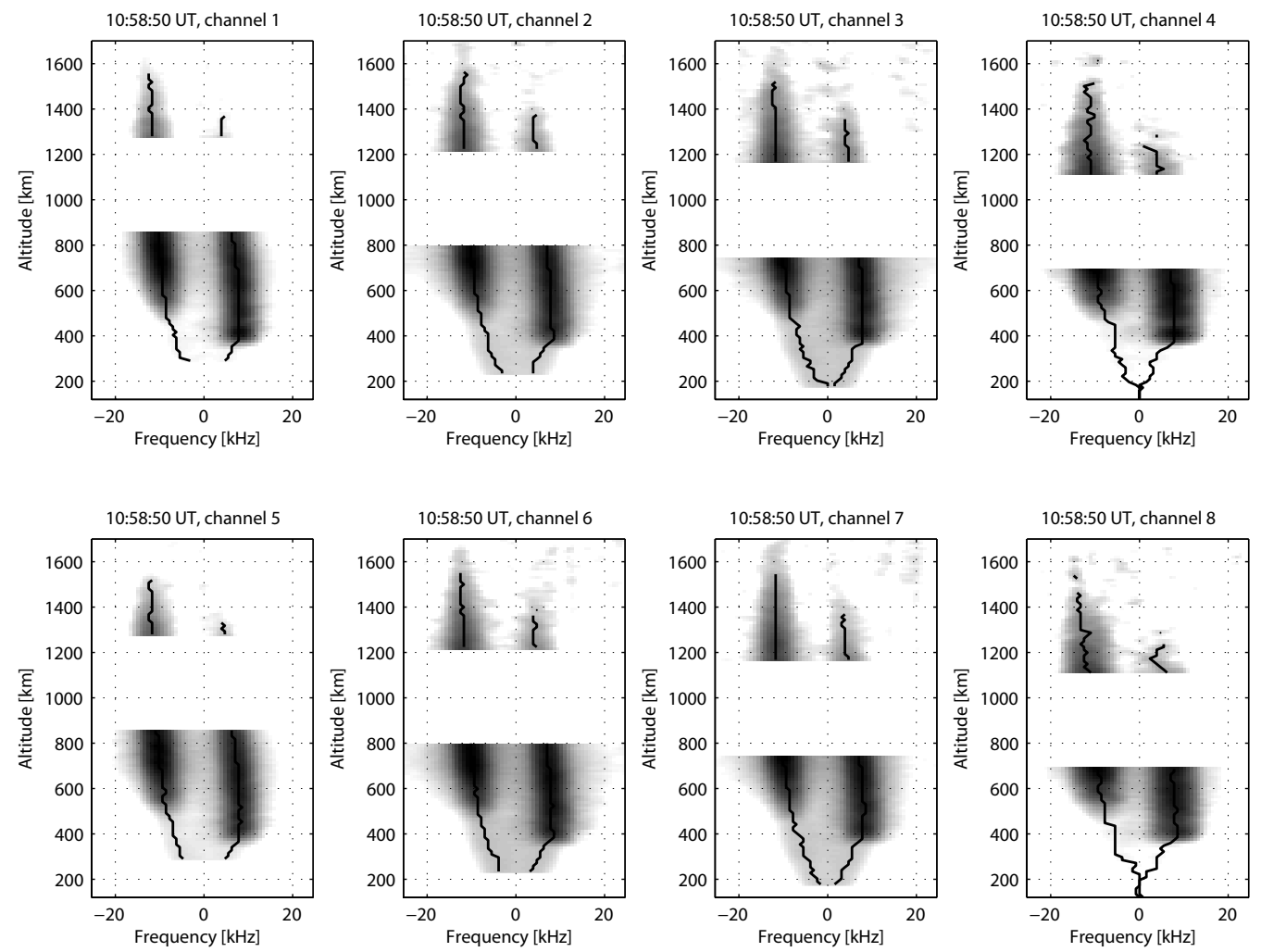

Fig. 2. Naturally enhanced ion-acoustic lines (NEIALs) observed with the ESR $32 \mathrm{~m}$ antenna at 10:58:50 UT on 28 July 2000 . Power spectra from channel 1 to channel 8 are plotted with a gray scale, over frequency on the $x$ axis and range on the $y$ axis. The black lines follow the positions of each of the ion-acoustic peaks.

Fig. 2. NEIALs are seen in all 8 channels, and are different between channels. Power spectra from channel 3, altitude $200-850 \mathrm{~km}$ and $1200-165 \mathrm{~km}$ (background) between 10:58:30 and 10:59:30 UT are plotted in Fig. 3. The received scattered power is inversely proportional to range squared, for incoherent scattering, and the spectral power has been multiplied by $r^{2}$ to correct for this effect. The $1 / r^{2}$ dependence might be an underestimate if scattering during NEIAL events is not weak, for example if multiple scattering occurs, as could be the case in a very turbulent plasma, or if the NEIALs are small compared to the scattering volume. The noise is approximately constant with height and time, but due to the range correction it appears to increase with increasing altitude. The spectra in Fig. 3 are normalized to a maximum value indicated at the top at each panel. For example, at 10:58:40 UT enhanced ion-acoustic lines are seen around $1200 \mathrm{~km}$ altitude, but they are not very strong and near the background noise level. In Figs. 2 and 3 we can also see how the location of both ion-acoustic peaks in frequency is traced over altitude.

The left, or downshifted, line in each spectrum corresponds to upgoing ion-acoustic waves, and right, or upshifted, line to downgoing waves. Downshifted NEIALs are frequently seen and are often also very strong. Upshifted lines seem to be less frequent and are also weaker than downshifted counterparts. This agrees with earlier UHF studies (Rietveld et al., 1991). Normal IS echoes are typically seen up to $800 \mathrm{~km}$ altitude.

The separation in frequency between the downshifted and upshifted ion lines always increases with altitude up to about $500 \mathrm{~km}$ altitude. Above $600 \mathrm{~km}$ altitude up to the data gap around $850 \mathrm{~km}$, the separation does not increase much any more. Adopting the interpretation that the separation between the ion-acoustic peaks is a rough indicator of the electron temperature (Forme and Fontaine, 1999), we suggest that electron temperature enhancements associated with NEIALs do not substantially increase any more above about $500 \mathrm{~km}$.

The center frequency between the downshifted and upshifted lines always moves towards lower frequencies with increasing altitude. In the case of normal IS echoes, this center frequency between the ion-acoustic spectral peaks indicates the bulk ion drift. We therefore think that the center frequency below zero seen in NEIALs indicates that the ions move upward increasingly fast with altitude. The downshifted peak seems to stay at about the same frequency above altitudes of $1200 \mathrm{~km}$ (e.g. 10:58:50 UT), but the upshifted peak gets close to zero frequency (e.g. 10:59:10 UT). We do 

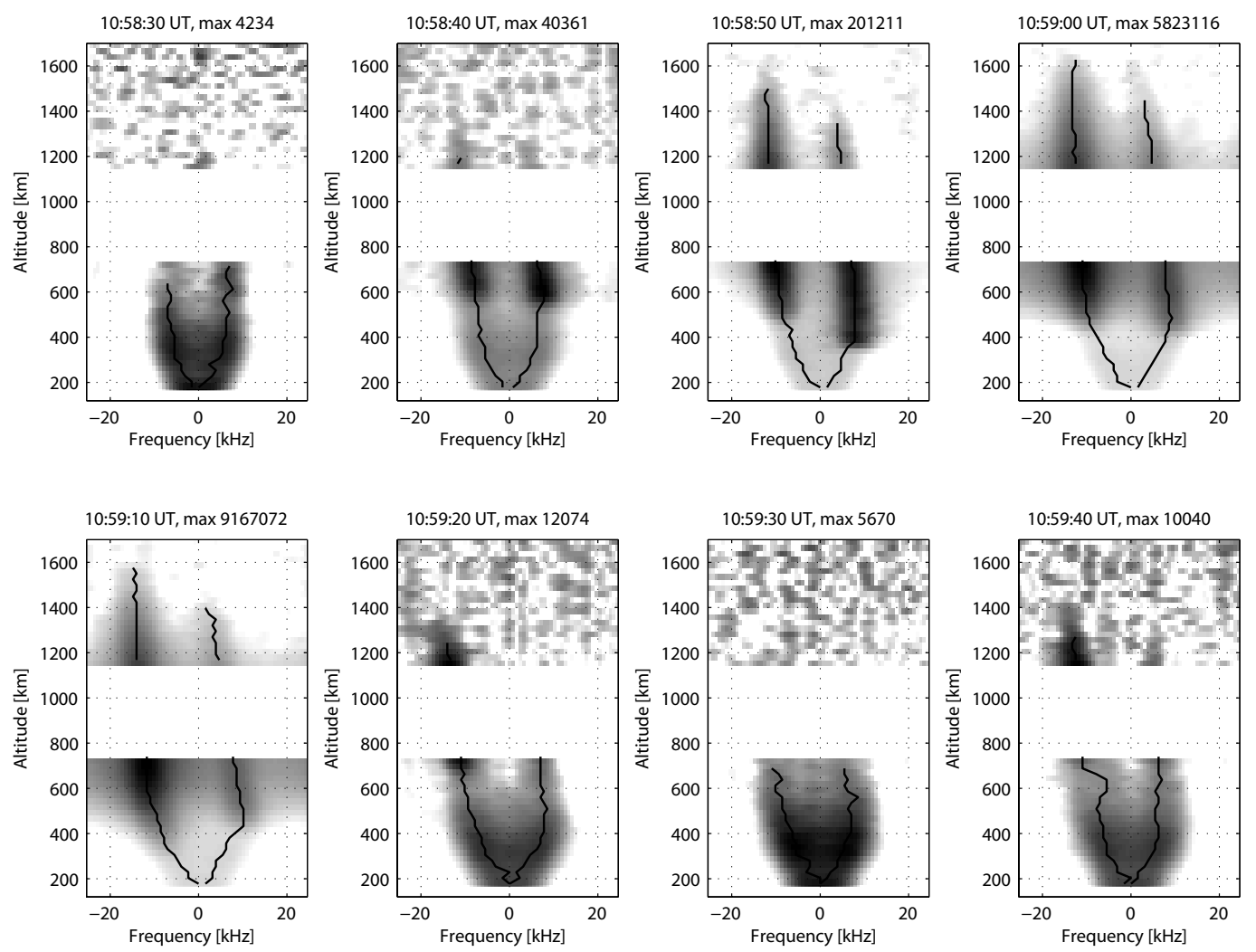

Fig. 3. NEIALs observed with the ESR $32 \mathrm{~m}$ antenna between 10:58:30 and 10:59:30 UT on 28 July 2000. Power spectra from channel 3, altitude $200-850 \mathrm{~km}$ and $1200-1650 \mathrm{~km}$ (background) are plotted with a gray scale. A format of the plots is same as Fig. 2. The spectra are multiplied by the range squared and normalized to the value given at the top.

not have data between $850 \mathrm{~km}$ and $1200 \mathrm{~km}$ altitude but generally the power and frequency of NEIALs can qualitatively be extrapolated from the lower to higher altitudes resulting in good agreement with the observations above $1200 \mathrm{~km}$. In other words, there are no indications of dramatic changes between $850 \mathrm{~km}$ and $1200 \mathrm{~km}$ in the interval where we have no data. Figure 4 shows analyzed ESR data between 09:00 and 11:30 UT on 28 July 2000 . The postintegration is $20 \mathrm{~s}$. From top to bottom the panels show: the electron density, the electron and ion temperatures and the field-aligned ion velocity. These parameters, from 150 to $800 \mathrm{~km}$ altitude, were obtained using the GUISDAP software package (Lehtinen and Huuskonen, 1996), used routinely for standard ESR data analysis, but we first removed data dumps containing NEIALs as well as spiky echoes. The later probably come from hard targets such as satellites and space debris. If the total received power increased above the $F 2$ peak significantly above the error bars then the data dump was considered to contain non-incoherent scatter contamination. Electron density enhancements around $300 \mathrm{~km}$ altitude are seen between 09:15 and 11:30 UT (Fig. 4a). These enhancements are deeply structured and also the electron temperature, $T_{e}$, is enhanced at this time (Fig. 4b). This indicates that the ionization is caused by the soft $(<1 \mathrm{keV})$ particle precipitation which is a typical feature of the cusp. The ion temperature $T_{i}$ is sometimes also enhanced, reaching more than $3000 \mathrm{~K}$ (e.g. at 09:20 and 10:10 UT, Fig. 4c). In these short ion heating events both the electron density $N_{e}$ and temperature $T_{e}$ are mostly lower than just before or just after the enhancement of $T_{i}$. The relative decrease of $N_{e}$ during high $T_{i}$ is probably due to enhanced convection causing higher relative convective and thermal (due to Joule heating) velocities between ions and neutrals and thus faster recombination (Ogawa et al., 2001). The relative decrease of $T_{e}$ indicates that the source of the electron heating, namely soft electron precipitation and/or plasma waves, is reduced during the periods of high convection and Joule heating. Data gaps due to the removal of NEIAL spectra are more rare when the ion temperature $T_{i}$ is high $(>3000 \mathrm{~K})$. The field-aligned ion velocity (Fig. 4d) is mainly upward above $400 \mathrm{~km}$ altitude, and the upward velocity increases with altitude. The upward ion velocity reaches about $600 \mathrm{~m} / \mathrm{s}$ at around $700 \mathrm{~km}$ altitude.

The maximum power in each peak and its location in frequency has been determined for both NEIAL and normal IS spectra. Results are shown in Fig. 5 for altitudes from $200 \mathrm{~km}$ up to $1600 \mathrm{~km}$. From top to bottom, the maximum power 


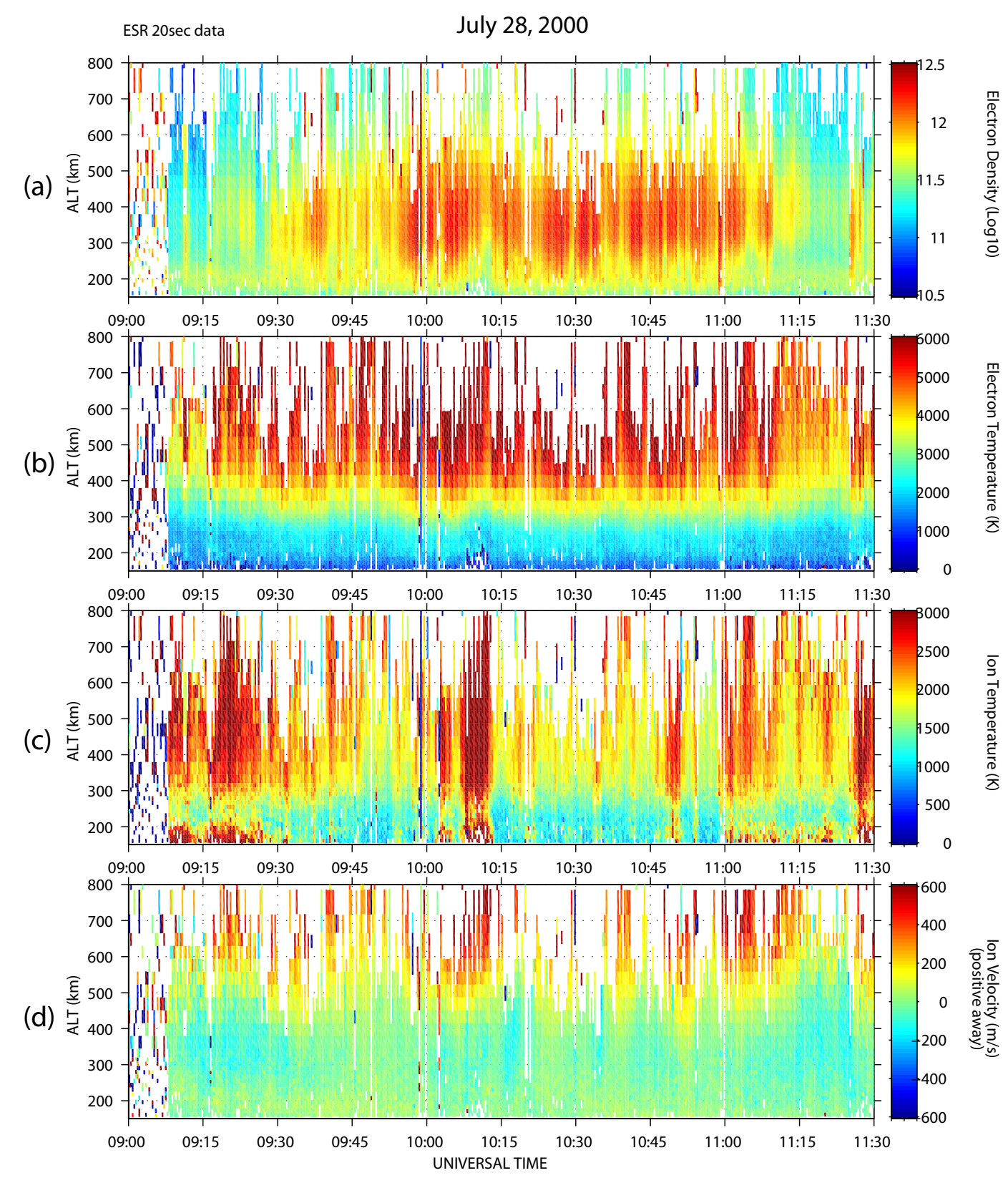

Fig. 4. Color-coded height-time profiles of $20 \mathrm{~s}$ integrated data obtained by the ESR between 09:00 and 11:30 UT on 28 July 2000. They are, from top to bottom: electron density, electron and ion temperatures, and the magnetic field aligned velocity, respectively.

of the downshifted line or upgoing wave (panel a), of the upshifted line or downgoing wave (panel $b$ ), the power ratio downshifted/upshifted (panel c), the difference upshifted minus downshifted in frequency (panel d), and the center frequency between the downshifted and upshifted peaks (panel e) are displayed color-coded over time and altitude.

High power in the downshifted peak is transiently seen throughout the time shown in Fig. 5a. High altitude (above $1200 \mathrm{~km}$ ) NEIAL events always correspond to low altitude (below $850 \mathrm{~km}$ ) events. The highest range corrected power along a profile is never seen above $1200 \mathrm{~km}$, but sometimes it seems likely to fall into the unobserved height range 850 to $1200 \mathrm{~km}$. The upshifted peak (Fig. 5b) is generally enhanced when there are also enhancements in the downshifted peak, but the enhancement is on average clearly less. From the power ratio (Fig. 5c) one can see that altitude where the upshifted peak is higher (dark blue color) is generally around $600 \mathrm{~km}$. However, between 400 and $800 \mathrm{~km}$ the power ratio is variable, sometimes the downshifted peak is higher than the upshifted one. Above $1000 \mathrm{~km}$, the downshifted peak is 
(a) $\log \left(\right.$ power of downshifted line $x \mathrm{r}^{2}$ )

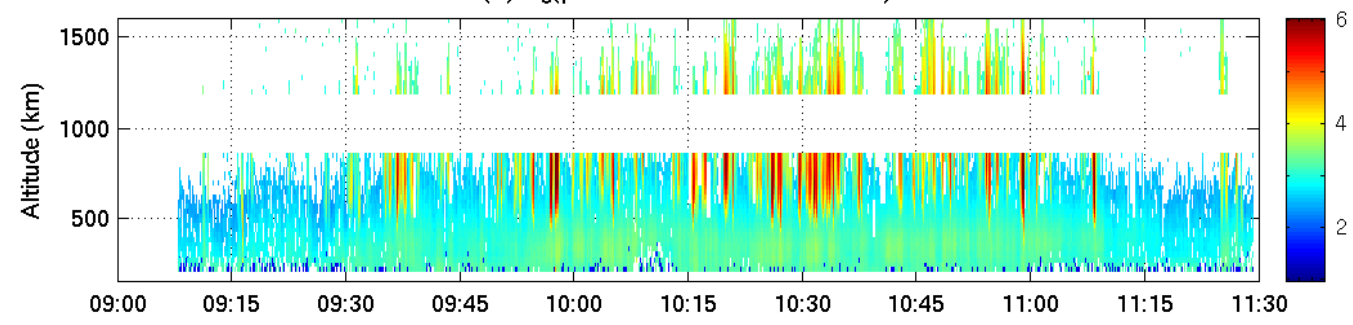

(b) $\log \left(\right.$ power of upshifted line $x r^{2}$ )

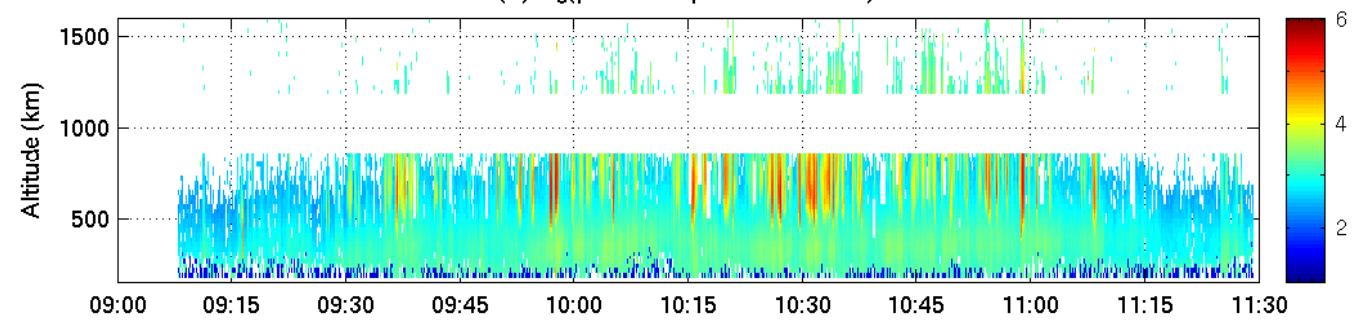

(c) $\log ($ downshifted line/ upshifted line)

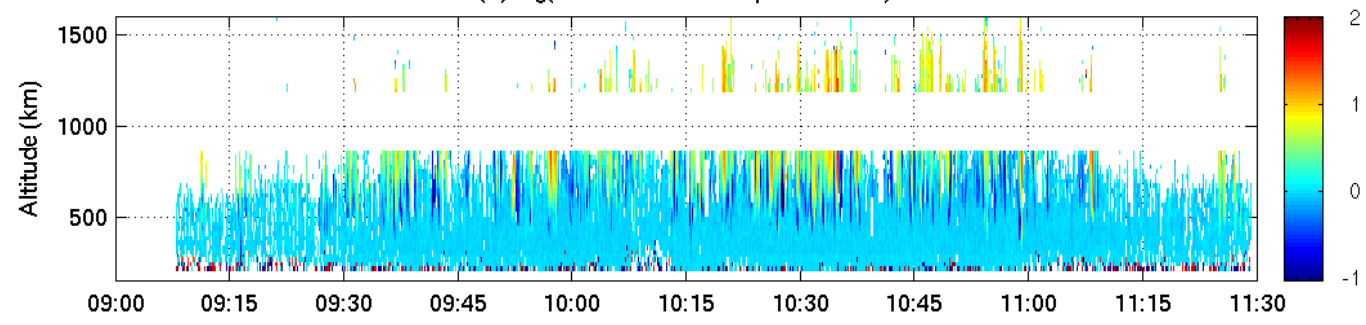

(d) difference of the spectral peaks $[\mathrm{kHz}]\left(\propto(\mathrm{Te}+\gamma \mathrm{Ti})^{1 / 2}\right)$

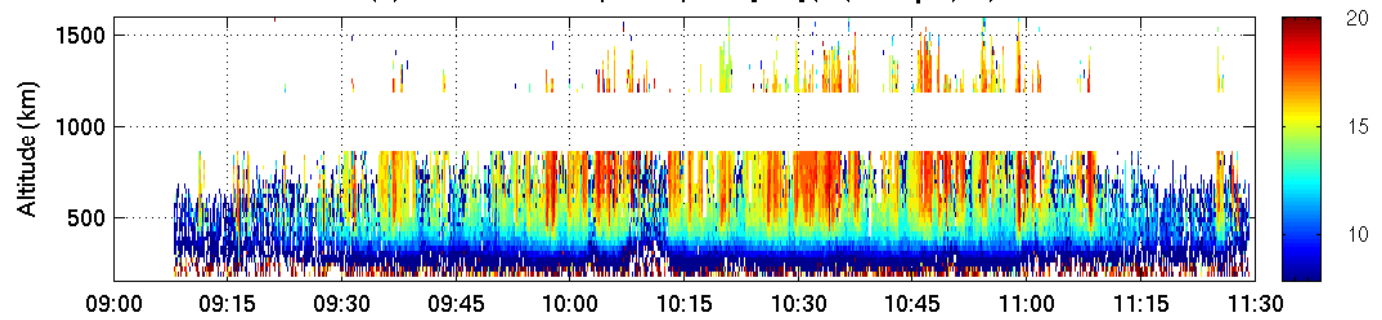

(e) center of the spectral peaks $[\mathrm{kHz}](\propto \mathrm{Vi})$

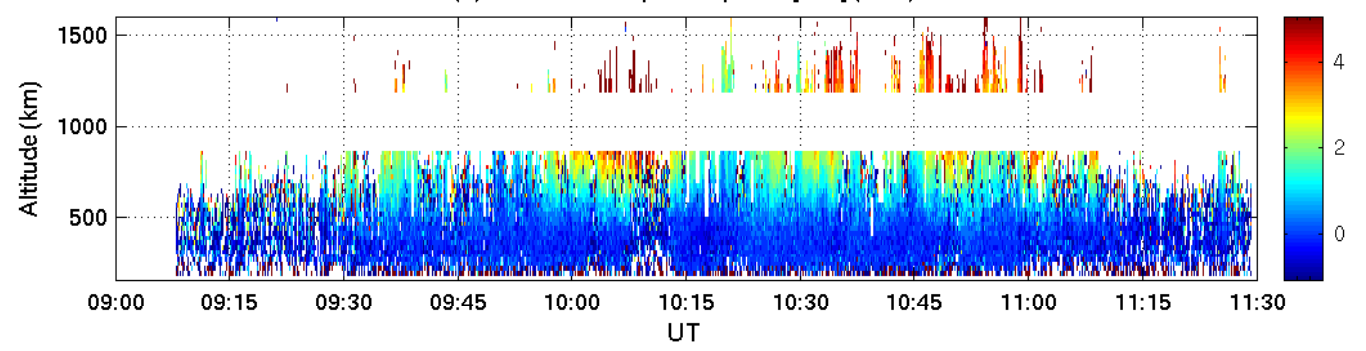

Fig. 5. Color-coded height-time profiles of $10 \mathrm{~s}$ raw data obtained by the ESR between 09:00 and 11:30 UT on 28 July 2000 . They are, from top to bottom, peak power of upgoing/downshifted line and of the downgoing/upshifted one, ratio of the downshifted to upshifted peak energies, distance in frequency between downshifted and upshifted peaks, and center frequency between the downshifted and upshifted peaks, respectively. 
always higher than the upshifted one.

The frequency difference between the two ion lines (Fig. 5d) seems to be correlated with occurrences of NEIALs. When the peak power of the ion lines becomes high, also the frequency difference is large. At around 10:10 UT, when the ion temperature is high due to strong Joule heating (see Fig. 4c), the frequency distance between lines is relatively small or even cannot be determined. This is because the ionacoustic shoulders of the IS spectrum merge into a single peak when $T_{i}$ is high. The highest separation between lines is generally in the $500-700 \mathrm{~km}$ altitude range, above $700 \mathrm{~km}$ the separation often decreases again. If we assume that the enhanced ion-acoustic waves are at the thermal ion-acoustic speed, then we can express the frequency difference $\delta f$ as follows:

$\delta f \propto \sqrt{\frac{k_{B}\left(\gamma T_{i}+T_{e}\right)}{m_{i}}}$

where $k_{B}$ is the Boltzmann constant, and $\gamma$ the ratio of specific heats. An increasing $\delta f$ up to about $600 \mathrm{~km}$, as it is seen in our data, can be attributed to electron heating and to a $T_{e}$ that is increasing with height. A similar correlation between $T_{e}$ and NEIALs has been found in other studies (Rietveld et al., 1991; Wahlund et al., 1992; Forme and Fontaine, 1999). However, in this study the data show that above about $700 \mathrm{~km}$ the electron temperature seems not to increase much any more. Above $1200 \mathrm{~km}$ a decreasing $\delta f$ is seen, indicating that $T_{e}$ is in fact decreasing. At high altitudes a possible hydrogen and/or helium ion contribution to the ion composition should lower the average ion mass $m_{i}$, causing an apparent wider separation between lines. In the observed spectra there is no visible signature of any significant $\mathrm{H}^{+}$or $\mathrm{He}^{+}$contribution; any such a contribution would decrease $T_{e}$, derived from $\delta f$, even more.

The center frequency $f_{c}$ between the two ion-acoustic lines (Fig. 5e) is interpreted as the Doppler frequency of the bulk ion drift $\mathrm{v}_{i}$ using the following equation:

$v_{i}=\lambda f_{c} / 2$

where $\lambda$ is the transmitted radio wavelength. Generally the velocity derived from the positions of enhanced lines using Eq. (2) is close to the bulk ion velocity fitted by the GUISDAP (see Fig. 4d) just before or just after the profiles with NEIALs. At high altitudes, where a comparison with the standard IS analysis is not possible, the velocity derived from the positions of the two enhanced ion-acoustic lines increases further with altitude and sometimes reaches $1500 \mathrm{~m} / \mathrm{s}$ at $1100 \mathrm{~km}$ altitude and higher. This is near to the ion-acoustic speed $c_{s}^{2}=k_{B}\left(T_{i}+T_{e}\right) / 2 m_{i}$.

Inspection of one of the strong NEIAL events illustrates these characteristics in more detail. Figure 6 shows six consecutive spectra from $10 \mathrm{~s}$ preintegrated data between 10:58:30 and 10:59:30 UT. In the left panels (Fig. 6a) grayscale-coded spectra are shown together with the ionacoustic line positions. From 10:58:40 to 10:59:10 UT, when the line enhancement is fully developed, both ion lines are seen up to about $1500 \mathrm{~km}$ altitude and their positions can be unambiguously determined. The next panel (Fig. 6b) shows the Doppler velocity (black line) and the ion-acoustic speed (dashed red line). The ion-acoustic speed $c_{s}$ is derived from the difference between the downshifted and upshifted peaks, $\delta f$, using

$c_{s}=\lambda \frac{\delta f}{4}$

The ion-acoustic speed reaches $3000 \mathrm{~m} / \mathrm{s}$ at $600 \mathrm{~km}$ altitude at 10:59:10 and 10:59:20 UT, and decreases above this maximum. The ion drift velocity increases with altitude from about $500 \mathrm{~km}$ all the way to $1600 \mathrm{~km}$, clearly exceeding $1200 \mathrm{~m} / \mathrm{s}$, which is about the ion-acoustic speed if there were no temperature enhancements. However, the ion drift is still subsonic when compared to the true ion-acoustic speed as derived from the observations. The determination of peak positions ends near $1600 \mathrm{~km}$ altitude, before the ion drift velocity exceeds the ion-acoustic speed, so we cannot be sure that this really happens. Extrapolation of the trends suggests that supersonic upflow would be reached above $2000 \mathrm{~km}$. In the next panel (Fig. 6c) the range corrected downshifted (black line) and upshifted (red line) power peaks are shown. For comparisons we add the peak power of the IS spectra at 10:20:10 UT (dashed line). Both downshifted and upshifted power increases with time until 10:59:10 UT and start to decrease at 10:59:20 UT. The highest power is seen near $700 \mathrm{~km}$. The downshifted line is stronger than the upshifted line except at low altitudes (below about $600 \mathrm{~km}$ ). As we have mentioned already above, the upgoing wave always dominates at high altitudes. In this event the enhancement of the downshifted line is more than 1000 times that of the IS ion line at the F region peak, and it must be more than 10000 times stronger than the local IS power which disappears in the noise. The final panels (Fig. 6d) show the ratio of the downshifted and upshifted spectral peaks. This ratio is near constant above $1200 \mathrm{~km}$ at 10:58:50 and 10:59:00 UT. But at 10:59:10 UT the downshifted/upshifted ratio decreases smoothly and slowly with altitude. The spectral power of NEIALs above $1100 \mathrm{~km}$ seems to decrease somewhat faster than $\exp (-h)$, while the normal IS power which is proportional to the electron density, does decrease linearly in the logarithmic plot, i.e. with $\exp (-h)$ (see the dashed line in Fig. 6c).

\subsection{Statistical analysis}

Using all identified double peak spectra from 09:00 to 11:30 UT we investigated how common and regular the characteristics discussed above are. Figure 7 shows results of this small statistical analysis. We have used only spectra containing NEIALs for the statistical analysis. Histograms of the Doppler velocity $v_{i}$ at 5 different altitudes are shown in the left panel (Fig. 7a). It needs to be kept in mind that at 
(a)
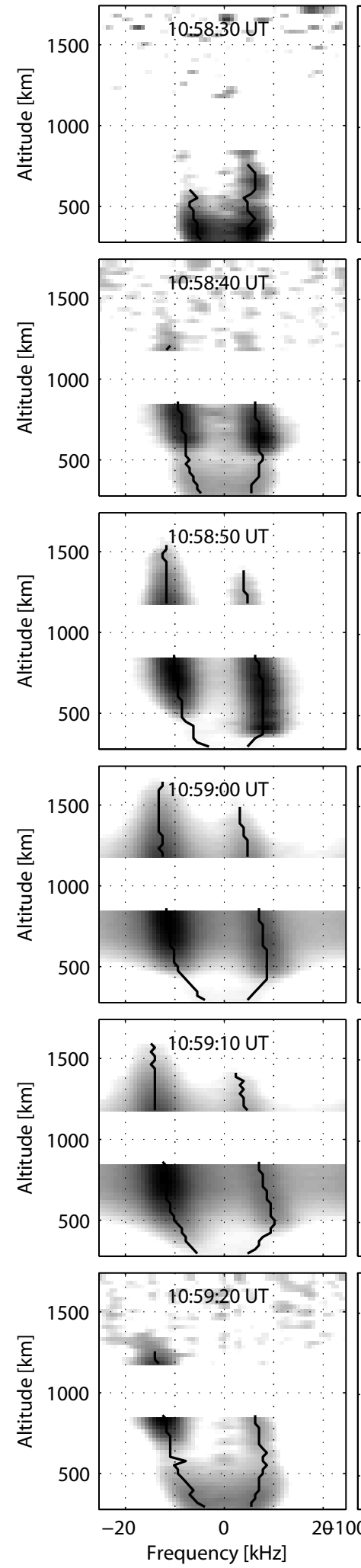

(b)

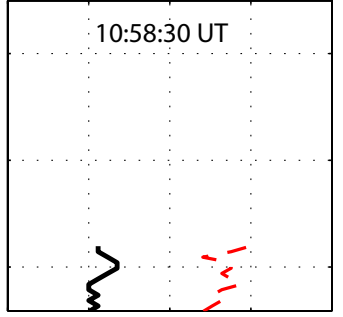

10:58:40 UT

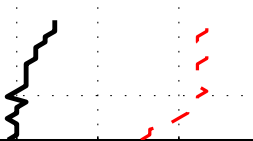

10:58:50 UT
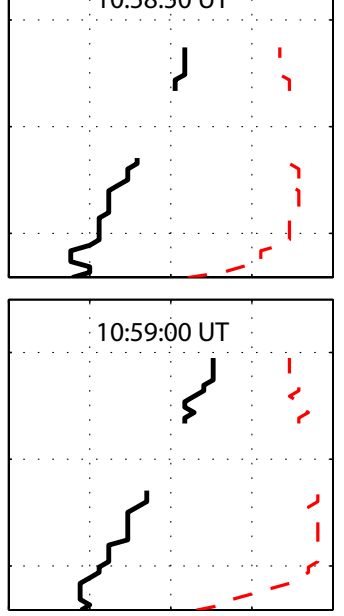

10:59:10 UT
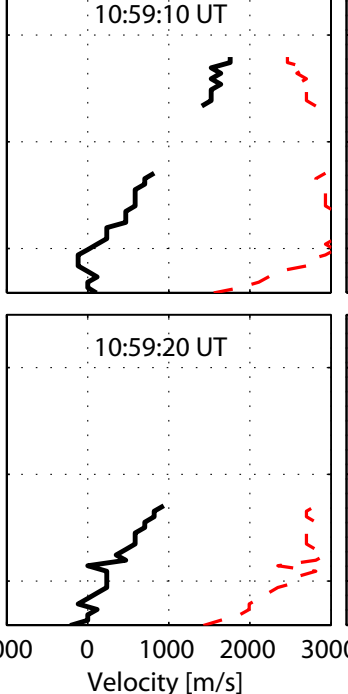

(c)
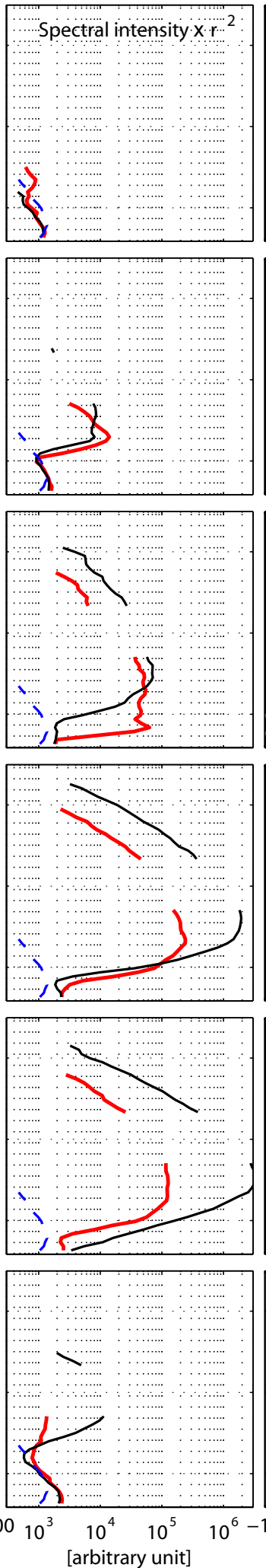

(d)
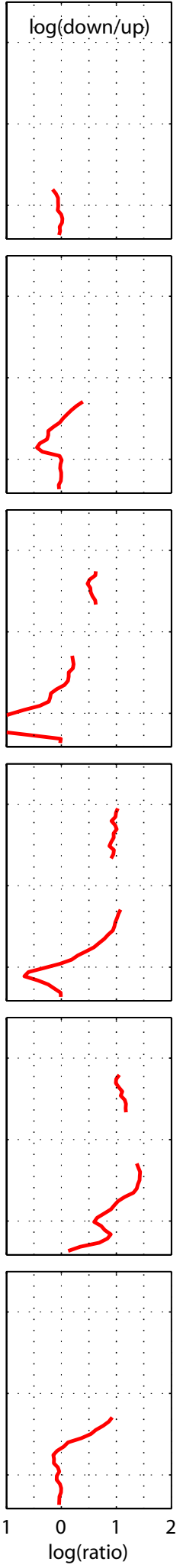

Fig. 6. (a) IS spectra, gray coded, between 10:58:30 and 10:59:30 UT on 28 July 2000. (b) Doppler velocity (black lines) and ion-acoustic speed (red dashed lines). (c) Peak power of upgoing (black) and downgoing (red) ion-acoustic lines. Normal IS signals (blue dashed line) at 10:20:10 UT are added to each plot. (d) The ratio of the downshifted to the upshifted peak. 
(a) $1250 \mathrm{~km}$ altitude

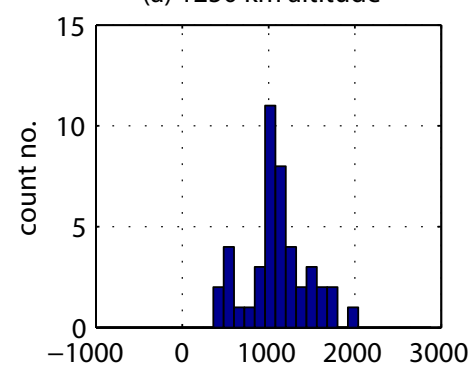

(a) $1200 \mathrm{~km}$ altitude

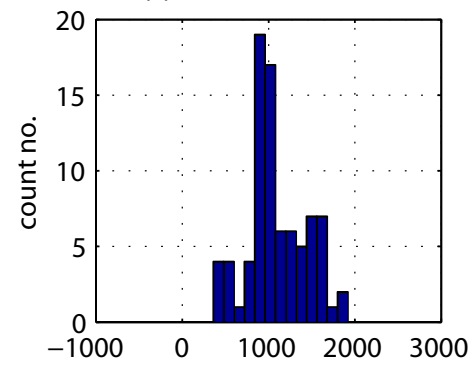

(a) $850 \mathrm{~km}$ altitude

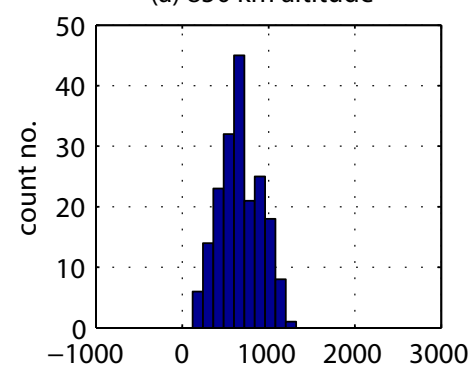

(a) $650 \mathrm{~km}$ altitude

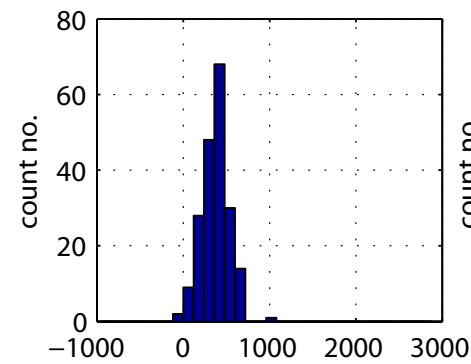

(a) $500 \mathrm{~km}$ altitude

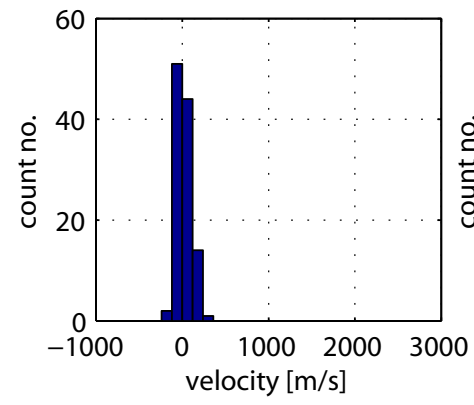

(b) $1250 \mathrm{~km}$ altitude

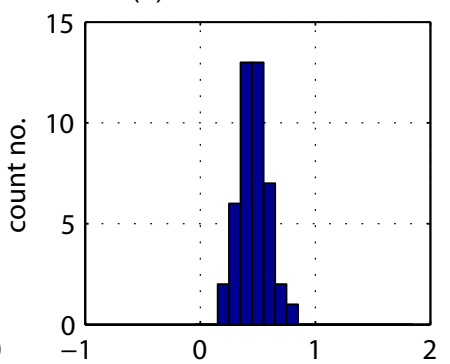

(b) $1200 \mathrm{~km}$ altitude

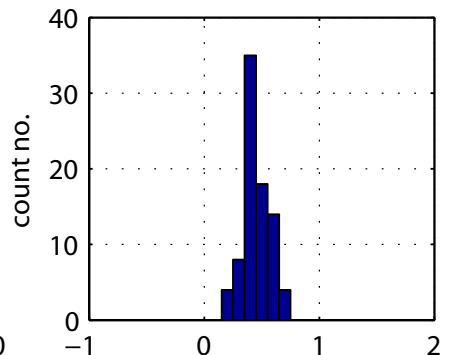

(b) $850 \mathrm{~km}$ altitude

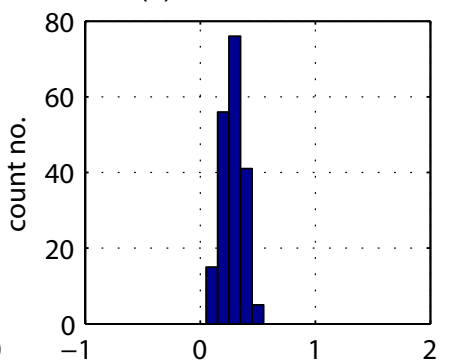

(b) $650 \mathrm{~km}$ altitude

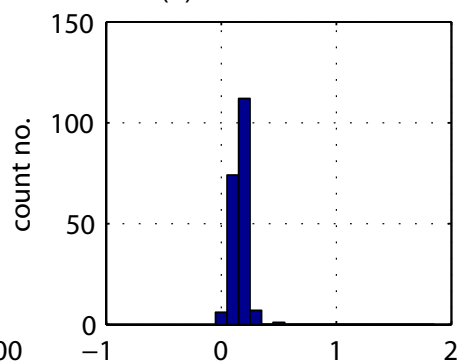

(b) $500 \mathrm{~km}$ altitude

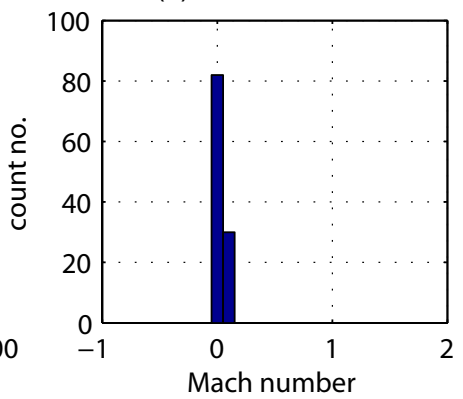

(c) $1250 \mathrm{~km}$ altitude

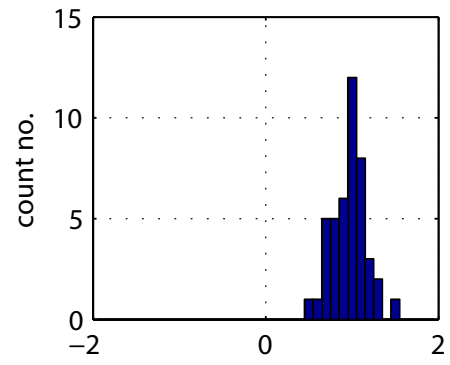

(c) $1200 \mathrm{~km}$ altitude

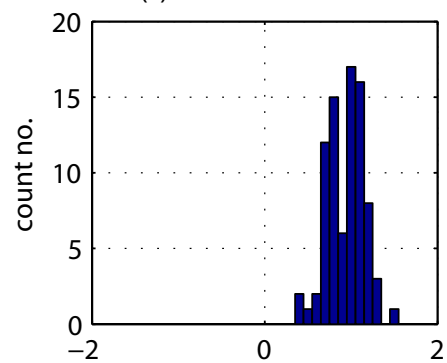

(c) $850 \mathrm{~km}$ altitude

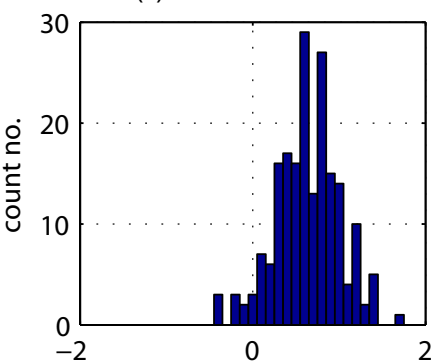

(c) $650 \mathrm{~km}$ altitude

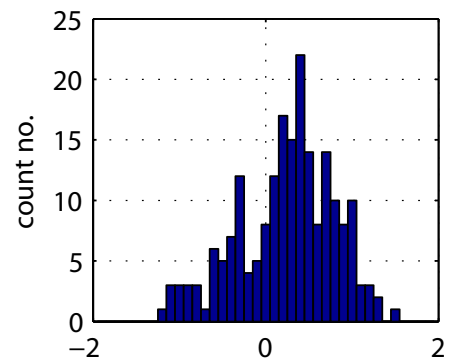

(c) $500 \mathrm{~km}$ altitude

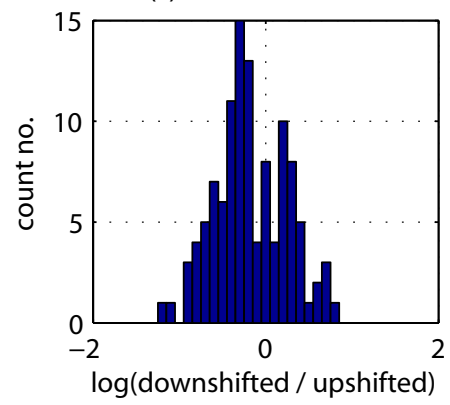

Fig. 7. Histograms of NEIAL parameters at altitudes of 500, 650, 850, 1200, $1250 \mathrm{~km}$ from 09:00 to 11:30 UT on $28 \mathrm{July} 2000$. The altitude span of the gates is $50 \mathrm{~km}$. (a) Doppler velocity. (b) Estimated Mach number. (c) Ratio of the downshifted to upshifted peak energy. 
(a)
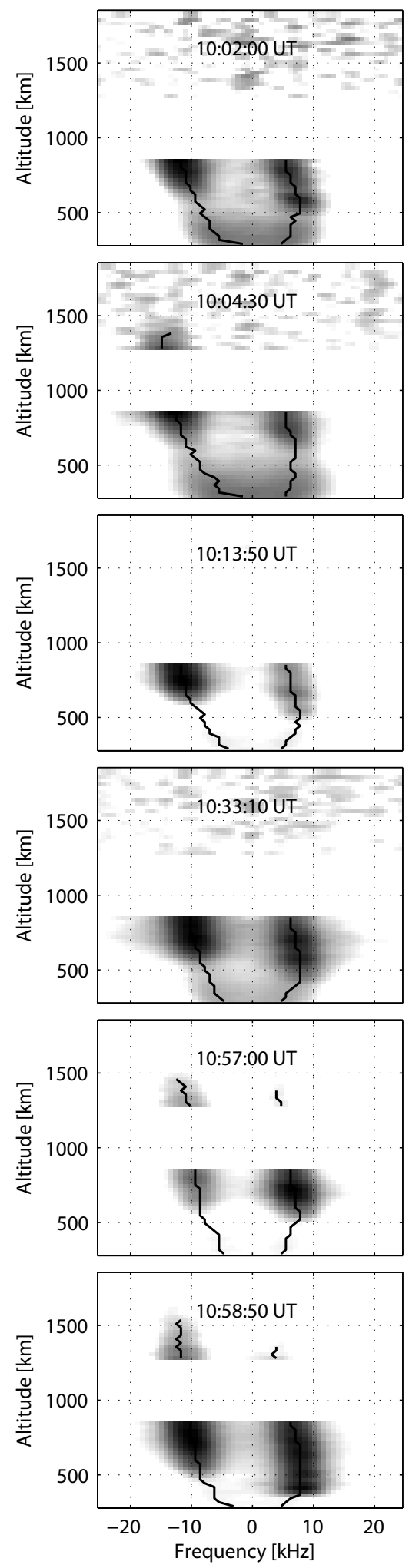

(b)
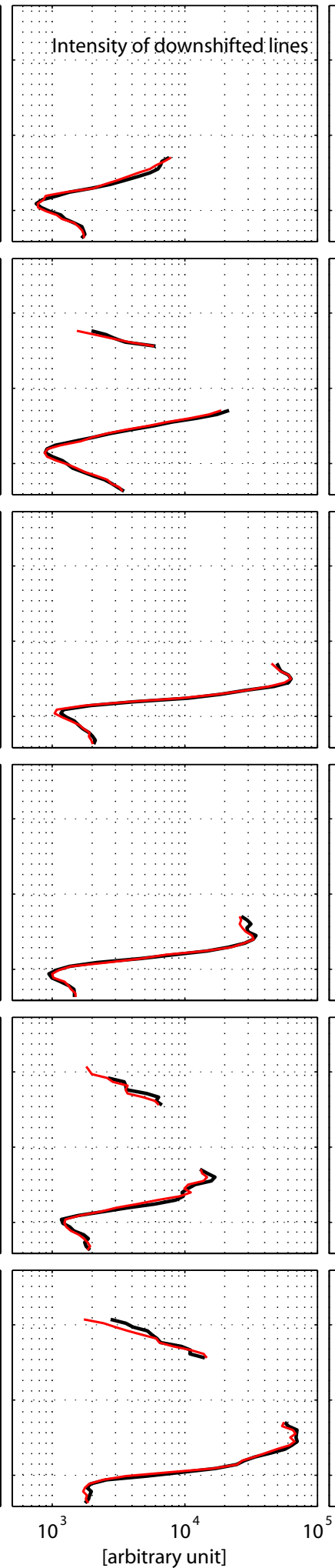

(c)
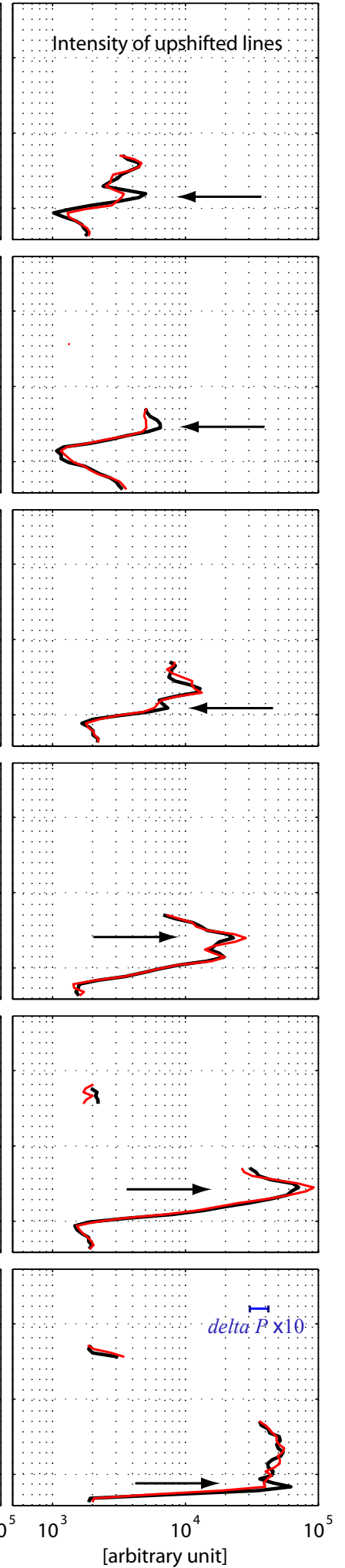

Fig. 8. Power of the NEIALs from channel 1 (Transmitting frequency of $498.1 \mathrm{MHz}$ ) and channel 5 (Transmitting frequency of $501.9 \mathrm{MHz}$ ) on 28 July 2000. (a) Gray coded IS spectra of channel 1. (b) Peak intensity (arbitrary units) of the downshifted ion-acoustic line in channel 1 (black line) and channel 5 (red line). (c) Same as (b), for the upshifted lines in channel 1 and channel 5. The arrows show where the intensities of the upshifted lines differ most between channels 1 and 5. 
the higher altitudes only enhanced lines are seen. Therefore the exclusively upward velocity at $1250 \mathrm{~km}$ indicates that NEIALs are always associated with an upward center velocity. It doesn't mean that there is a steady upward flow (polar wind, e.g. Abe et al., 1993). The middle panel (Fig. 7b) shows the ion-acoustic Mach number $M$ defined by

$M=\frac{v_{i}}{c_{S}}$

Where $c_{s}$ is defined in Eq. (3). The average $M$ increases steadily with altitude and becomes about 0.5 at $1250 \mathrm{~km}$. In a few cases $M$ is close to, but never exceeds unity. The right panel (Fig. 7c) shows the ratio of the downshifted and upshifted ion-acoustic peaks. At $1200 \mathrm{~km}$ and above the upshifted line is never stronger than the downshifted one, on average the downshifted peak has about 8 times higher energy than the upshifted one.

\subsection{Frequency dependence revisited}

Data from 8 different transmitter frequencies and receiver channels are available. The largest difference in frequency is $3.8 \mathrm{MHz}$. Differences between the channels for "normal" data below $900 \mathrm{~km}$ were investigated and reported by Ogawa et al. (2000b). We have looked at differences between channels of NEIALs in the background gates above $1200 \mathrm{~km}$, but they are not greater than at lower altitudes. However, we found that by separating up- and downshifted lines, and calculating the power therein, the differences between channels become somewhat clearer than for the total ion line power shown in Ogawa et al. (2000b). Figure 7 shows examples comparing channel $1(498.1 \mathrm{MHz})$ and in channel $5(501.9 \mathrm{MHz})$. On this scale, the background noise power is around $10^{3}$. The (mostly weaker) upshifted line reaches a signal-to-noise ratio of 20 and more. The intensity of the upshifted line varies with altitude more strongly than the downshifted line, and the observed variations are probably limited by the poor range resolution of the long pulse $(54 \mathrm{~km})$. When we compare data from channels 4 and 8 (which have the short pulse length, $22.5 \mathrm{~km}$ ), the variations became higher although their separation in frequency is less (see Fig. 2). Near the altitude of the maximum enhanced power (400-800 km) differences identified by arrows between channels 1 and 5 are seen that clearly exceed the 1 $\sigma$ standard deviation $\delta P / P$ (Ogawa et al., 2000b); $\delta P / P$ is estimated from

$$
\frac{\delta P}{P}=\frac{1}{\sqrt{N}}\left(1+\frac{1}{S N R}\right)
$$

where $N$ is the number of samples or pulses in the integration period and $S N R$ the signal-to-noise ratio. The differences do not favor either the lower or higher wave number in any systematic manner.

\section{Discussion and conclusions}

We have found that the background gates of the gup0 program can be contaminated by strongly enhanced ion-acoustic lines at altitudes between 1200 and $1900 \mathrm{~km}$. This allows us to investigate the characteristics of these lines at high altitudes which have not been considered before. VHF data certainly also contain measurements of NEIALs above $1000 \mathrm{~km}$, but a systematic study has not been undertaken yet and would suffer from the deviation of the VHF antenna beam from the field-aligned direction which is the most interesting one.

The lines seen with the ESR above $1200 \mathrm{~km}$ are strongly enhanced while the incoherently scattered signal is no longer detectable in the noise. Under these strong enhancements both upshifted and downshifted ion-acoustic lines are always seen; the downshifted line, corresponding to upgoing waves, always dominates. The appearance of always both lines whenever there is strong enhancement is naturally explained by a parametric decay model as suggested by Forme (1993). It involves the decay of a non-linear Langmuir wave into another Langmuir wave and an ion-acoustic wave. In this model the weaker line is due to a secondary decay involving the same types of waves, but with opposite propagation directions. The primary non-linear Langmuir waves are thought to be caused by electron beams, and corresponding positive slope in the electron velocity distribution function, and they propagate in the same direction as the beam. In order to explain a stronger downshifted line with the Langmuir decay model, the beam has to be upward. Therefore it cannot be a form of electron precipitation into the ionosphere. Previously it has been suggested that electron precipitation causes enhanced ionization in the ionosphere and produces secondary electrons which move upward and cause Langmuir waves that are strong enough to decay. Between 1200 and $1900 \mathrm{~km}$ we observe a systematic asymmetry favoring upgoing waves even more clearly than at altitudes below $900 \mathrm{~km}$. How this, and the features summarized below, fit quantitatively into the Langmuir wave decay model remains to be clarified. The preference for up or downgoing waves seems to coincide approximately with the direction of the large scale density gradient. Below the $F$ region peak downgoing waves are more frequent (Rietveld et al., 1991, 1996), and above, upgoing ones. The density gradient is a source of free energy and it is enhanced by soft precipitation causing extra ionization. Because its scale is so much larger than the wavelengths of ion-acoustic and Langmuir waves, it seems unlikely that the density gradient is directly driving the waves, but perhaps the gradient direction somehow controls the microphysical processes generating the waves.

Power variations among different receiver channels still cause us to suspect that the ion-acoustic wave enhancements are highly structured over wavelength (Ogawa et al., 2000b). The model of Langmuir wave decay produces strong waves over only a limited range of wavelengths, requiring a positive slope in the electron distribution function at a phase 
velocity approximately $\omega_{p e} / k_{l}$ over a velocity interval $\delta v$, where $\omega_{p e}$ is the electron plasma frequency, and $k_{l}$ the average wave number of Langmuir waves. It is assumed that the wave length is much larger than the Debye length, $k_{l} \lambda_{D e}<1$. Then the waves are expected to have a range of wave numbers $\delta \mathrm{k} \approx \omega_{p e} / \delta v$ centered around $k_{l}$. Ion-acoustic waves from a Langmuir wave decay have about twice the wave number, $k_{i a} \approx \mathrm{k}_{l}$. Correspondingly, the spread in ion-acoustic wave numbers is about $2 \omega_{p e} / \delta v$. Intense waves are expected for a steep, localized slope in the distribution function, and the waves would then be concentrated in a relatively narrow range of wave numbers. However, we think that the limited observational evidence does not exclude the possibility that the wave number spectrum has for example, a Kolmogoroff type power law shape (as shown for example in Kelly, 1989, p392). Turbulence resulting from intense field-aligned currents would perhaps produce such a spectrum, but sharp structures in $k$ space might still be observed intermittently. In summary, both the enhancement of the downshifted line whenever the upshifted line is strongly enhanced, and the dependence of the enhancement on radar wavelength are features expected for a beam driven turbulence where parametric decay occurs.

The highest scattered power comes typically from the altitude range about $600-800 \mathrm{~km}$, which is above the $F$ region density peak and below the height window of the gup0 background gates $(1200-1900 \mathrm{~km})$. At high altitudes the enhanced power must reach more than 10000 times the incoherent scattered power in some of the events of this study. If the size of the enhanced scattering region perpendicular to the magnetic field were smaller than the area illuminated by the antenna beam, as found for events studied by Grydeland et al. (2003), then the enhancement factor would be even larger, perhaps as much as $10000 \times 100$.

The separation between the downshifted and upshifted ion-acoustic peaks decreases at high altitudes indicating that electron temperature enhancements are greatest roughly at the altitude of maximum power enhancement. Overall, the ion-acoustic peaks become increasingly downshifted with height, indicating that the bulk ion upflow speed increasing up to and beyond, the highest received altitude. The ionacoustic speed (sound velocity) is not exceeded; however, an extrapolation of the velocity profiles suggests that the ion upflow becomes supersonic not far above the highest received altitude $(1600 \mathrm{~km})$ in at least one event. Expansion of the upflowing plasma should qualitatively lead to cooling (see discussions of the solar corona expansion/solar wind in textbooks, e.g. Parks, 1991). The cooling competes with heating from waves. Our observation that near the (indirectly determined) temperature maximum the waves also seem to be most intense suggests that electrons are heated not only by particle precipitation, but also by waves. Waves in connection with up- and outflowing ions have been observed in the topside ionosphere by several sounding rockets and satellites (Yau and André, 1997; and references therein). In particular data from the Freja satellite and the SCIFER sounding rocket have shown a clear relation between ion acceleration and plasma waves above $1000 \mathrm{~km}$ up to $1800 \mathrm{~km}$ altitude, around the dayside cusp/cleft region (e.g. Bonnell et al., 1996; André et al., 1998). Our NEIAL observations suggest that at higher altitudes cooling due to upflow and expansion, as in the solar corona, seems to be important.

In the future we plan to look for NEIALs not only in ESR background data, but also in the background measurements of the Troms $\emptyset$ radars.

Acknowledgements. We are indebted to the director and staff of EISCAT for operating the facility and supplying the data. EISCAT is an International Association supported by Finland (SA), France (CNRS), Germany (MPG), Japan (NIPR), Norway (NFR), Sweden (NFR) and the United Kingdom (PPARC). This research was financially supported by the Grant-in-Aid for Scientific Research B $(16340146,17340145,18403010$, and 18740310) by the Ministry of Education, Science, Sports and Culture, Japan, and by the Swedish National Space Board. We especially thank T. Grydeland for his great help and discussions.

Topical Editor M. Pinnock thanks T. van Eyken and M. Rietveld for their help in evaluating this paper.

\section{References}

Abe, T., B. A., Whalen, A. W., Yau, R. E., Horita, S. Watanabe, and E. Sagawa: EXOS D (Akebono) suprathermal mass spectrometer observations of the polar wind, J. Geophys. Res., 98, 11 191$11203,1993$.

André, M., Norqvist, P., Andersson, L., Eliasson, L., Eriksson, A. I., Blomberg, L., Erlandson, R. E., and Waldemark, J.: Ion energization mechanisms at $1700 \mathrm{~km}$ in the auroral region, J. Geophys. Res., 103, 4199-4222, 1998.

Bonnell, J., Kintner, P., Wahl, J. E., Lynch, K., and Arnoldy, R.: Interferometric determination of broadband ELF wave phase velocity within a region of transverse auroral ion acceleration, Geophys. Res. Lett., 23, 3297-3300, 1996.

Buchert, S. C., van Eyken, A. P., Ogawa, T., and Watanabe, S.: Naturally enhanced ion-acoustic lines seen with the EISCAT Svalbard Radar, Adv. Space Res., 23, 1699-1704, 1999.

Cabrit, B., Opgenoorth, H., and W. Kofman: Comparison between EISCAT UHF and VHF backscattering cross section, J. Geophys. Res., 101, 2369-2376, 1996.

Collis, P. N., Häggström, I., Kaila, K., and Rietveld, M.: T. EISCAT radar observations of enhanced incoherent scatter spectra: Their relation to red aurora and field-aligned currents, Geophys. Res. Lett., 18, 1031-1034, 1991.

Forme, F. R. E.: A new interpretation on the origin of enhanced ion-acoustic fluctuations in the upper ionosphere, Geophys. Res. Lett., 20, 2347-2350, 1993.

Forme, F. R. E. and Fontaine, D.: Enhanced ion-acoustic fluctuations and ion outflow, Ann. Geophys., 17, 189-190, 1999.

Foster, J. C., del Pozo, C., Groves, K., Maurice, J.-P., St.: Radar observations of the onset of current driven instabilities in the topside ionosphere, Geophys. Res. Lett., 15, 160-163, 1988.

Grydeland, T., La Hoz, C., Hagfors, T., Blixt, E. M.,Saito, S., Strømme, A., and Brekke, A.: Interferometric observations 
of filamentary structures associated with plasma instability in the auroral ionosphere, Geophys. Res. Lett., 30, 1338, doi:10.1029/2002GL016362, 2003.

Grydeland, T., Blixt, E. M., Løvhaug, U. P., Hagfors, T., La Hoz, C., and Trondsen, T. S.: Interferometric radar observations of filamented structures due to plasma instabilities and their relation to dynamic auroral rays, Ann. Geophys., 22, 1115-1132, 2004.

Kelly, M. C.: The Earth's Ionosphere: Plasma Physics and Electrodynamics, Academic Press, San Diego, 1989.

Lehtinen, M. S. and Huuskonen, A.: General incoherent scatter analysis and GUISDAP, J. Atmos. Terr. Phys., 58, 435-452, 1996.

Ogawa, Y., Fujii, R., Buchert, S. C., Nozawa, S., Watanabe, S., and van Eyken, A. P.: Simultaneous EISCAT Svalbard and VHF radar observations of ion upflows at different aspect angles, Geophys. Res. Lett., 27, 81-84, 2000a.

Ogawa, Y., Forme, F. and Buchert, S. C.: Frequency dependent power fluctuations: a feature of the ESR system or physical?, Ann. Geophys., 18, 1224-1230, 2000b.

Ogawa, T., Buchert, S. C., Nishitani, N., Sato, N., and Lester, M.: Plasma density suppression process around the Cusp revealed by simultaneous CUTLASS and EISCAT Svalbard Radar observations, J. Geophys. Res., 106, 5551-5564, 2001.

Parks, G. K.: Physics of space plasmas - an introduction, AddisonWesley Publishing Co., Redwood City, CA,1991.

Rietveld, M. T., Collis, P. N., and Maurice, J.-P. St.: Naturally enhanced ion-acoustic waves in the auroral ionosphere observed with the EISCAT 933 MHz radar, J. Geophys. Res., 96, 1929119305, 1991.

Rietveld, M. T., Collis, P. N., van Eyken, A. P., and Løvhaug, U. P.: Coherent echoes during EISCAT UHF Common Programmes, J. Atmos. Terr. Phys., 58, 161-174, 1996.
Rietveld, M. T., Isham, B., Grydeland, T., La Hoz, C., Leyser, T. B., Honary, F., Ueda, H., Kosch, M., and Hagfors, T.: HFPump-induced parametric instabilities in the auroral E-region, Adv. Space. Res., 29, 1363-1368, 2002.

Sedgemore-Schulthess, K. J. F., Lockwood, M., Trondsen, T. S., Lanchester, B. S., Rees, M. H., Lorentzen, D. A., and Moen, J.: Coherent EISCAT Svalbard Radar spectra from the dayside cusp/cleft and their implications for transient field-aligned currents, J. Geophys. Res., 104, 24 613-24 624, 1999.

Sedgemore-Schulthess, F. and St.-Maurice, J.-P.: Naturally enhanced ion-acoustic spectra and their interpretation, Surv. Geophys., 22, 55-92, doi:10.1023/A:1010691026863, 2001.

Strømme, A., Belyey, V., Grydeland, T., La Hoz, C., Lovhaug, U. P., and Isham, B.: Evidence of naturally occurring wave-wave interactions in the polar ionosphere and its relation to naturally enhanced ion acoustic lines, Geophys. Res. Lett., 32, L05103, doi:10.1029/2004GL020239, 2005.

Wahlund, J.-E., Opgenoorth, H. J., Häggström, I., Winser, K. J., and Jones, G. O. L.: EISCAT observations of topside ionospheric ion outflows during auroral activity: Revisited, J. Geophys. Res., 97, 3019-3037, 1992.

Wannberg, G., Wolf, I., Vanhainen, L.-G., Koskenniemi, K., Rottger, J., Postila, M., Markkanen, J., Jacobsen, R., Stenberg, A., Larsen, R., Eliassen, S., Heck, S., and Huuskonen, A.: The EISCAT Svalbard radar: A case study in modern incoherent scatter radar system design, Radio Sci., 32, 2283-2308, 1997.

Yau, A. W. and André, M.: Sources of ion outflow in the high latitude ionosphere, Space Sci. Rev., 80, 1-25, 1997. 